\title{
STUDY ON THE SPECTATORS' PERCEPTION REGARDING THEIR DEMANDS AND NEEDS IN RELATION TO THE PROMOTION OF THE EVENTS THEY PARTICIPATE IN
}

\author{
Ababei Cătălina ${ }^{1}$ \\ 1"Vasile Alecsandri" University of Bacău, 157, Calea Mărășești, 600115, Romania
}

Keywords: competition, satisfaction, advertising.

\begin{abstract}
Sports fans represent a very important mechanism for sports organizations. They are the ambassadors of the brand in a manner that is envied by many consumer-orientated organizations. The love for sport shows a different kind of loyalty that is hard to reproduce in other consumer products. Sports fanatics will always follow their favorite team, for better or worse. They will always support their favorite team because it is in their blood. They associate themselves with the qualities of their favorite team. In fact, their whole identity is associated and mixed with the team's identity. The fans and supporter groups are, thus, a very important factor when we are talking about public relations and communication in sports. This study tries to determine the fundamental elements for the sports events to have as many spectators as possible, which later could become true supporters.
\end{abstract}

\section{Introduction}

Grunig and Hunt (1984) write that the first step in a public relations strategy is the identification of all individuals or groups that are involved with the organization. This can be done by "scanning" the environment using polls, studying the media, consulting the political leaders and the local community leaders, using internal archives and management information. The scanning of the environment should result in a list of people involved whom can be graded according to the degree of influence they have on the organization, or according to how much they think the organization should moderate its impact on them. The resources should be allocated according to this grading, the people with the highest grades receiving the most attention. In addition to managing its relationship with the factors involved, it is very important for an organization to pay special attention to the strategic audiences. The audiences are not selected, but evolve according to the situations. As these audiences emerge, each will be differently interested in the problem.

Cutlip et al. (2006) examine the process of strategic definition of the audiences, claiming that "the key in defining the strategic audiences is the 
identification of the way in which the people are involved and affected by the situation for which the intervention program is conceived, necessitating more effort in gathering information than just cataloging groups of people with seemingly something in common." The authors add that it is important to understand "what they know, what they feel, and what they do in relation to who and where they are" in order to have useful goals for each target audience. This only reinforces Grunig and Hunt's idea that one needs a bilateral communication to identify the audiences and their point of view regarding the problems that emerge when organizations are looking to build solid and durable relationships with the key audiences. The governments, the associations, the sports arenas managers, the employees, the sponsors, the media representatives are examples of involved audiences.

\section{Material and Methods}

This paper aimed to identify the sports audience's perception regarding its demands and needs in order to become loyal spectators of a sport or sports events in general.

Hypothesis. This research started from the following hypothesis: the emphasis of the importance of aspects related to the demands of sports audience could help sports organizations make spectators loyal and even determine them to be actively involved in the top performance activity.

Research objectives: The research had the following main objectives: to gather information through an inquiry, to create a questionnaire and validate the questions, to establish the research group and location.

Research development. The research was conducted in March 2016, on a group of 298 spectators/supporters of the handball competitions of the Balonmano Club of Elche, Spain. The research was conducted with the direct support of the coaches in above-mentioned club, this author being at the same time a teacher at the Miguel Hernandez University of Elche, Spain. This sport was chosen because in that period of time handball had the most competitions, its spectators being easier to inquire in regards to the importance of the way in which the communication is made between the public and the members of the organization. This research was conducted on a foreign audience, with the intention to be applied also on Romanian spectators, to see the similarities and especially the differences of opinion regarding the above-mentioned aspects.

Methods. The main research method was the inquiry, and the working instrument was the sociological questionnaire. This was applied directly, before the games. The questionnaire had 32 questions, comprising:

a) identification questions;

b) factual questions (which show behavioral elements of the subjects);

c) knowledge questions (which identify the subjects' knowledge regarding a particular issue);

The internal consistency was measured by calculating the Cronbach alpha coefficient for a group of 298 people. The measurements resulted in a value of 
0.713 , within the confidence interval, with a minimum value of 0.663 and a maximum value of 0.758 , which is an acceptable statistical value in regards to the measurement of the internal consistency through this index. (Cronbach, 1977). This value indicates that the items tend to measure the same variables.

For this paper, only 6 of the 32 questions were selected, the ones regarding how important are certain aspects that could become determining factors in making loyal fans of an audience. All the participants to this study were volunteers. The data was recorded and analyzed using the SPSS software. This study will refer to the following set of questions:

1. How IMPORTANT is the way in which the tickets are available for your favorite team's games?

Not at all

important

Much less

important

Less important

Largely

Very important

2. How IMPORTANT is for you to get ahead of time the tickets for your favorite team's games?

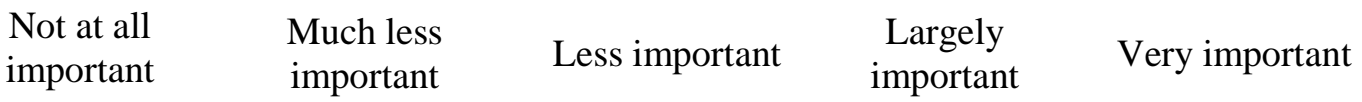

3. How IMPORTANT is for you to come with another person to the game?

$\begin{array}{lllll}\text { Not at all } & \text { Much less } & \text { Less important } & \begin{array}{c}\text { Largely } \\ \text { important }\end{array} & \text { Very important }\end{array}$

4. How IMPORTANT is your motivation in deciding to go to a game?

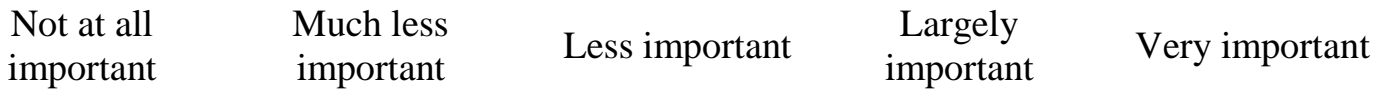

5. How IMPORTANT is for you to feel the pleasure/satisfaction of being there during a game?
Not at all
Much less
important
important
Less important
Largely
important
Very important

6. How IMPORTANT are for you the aspects that would determine you not to go to a game?
Not at all important
Much less
important
Less important
Largely important
Very important 


\section{Results and Discussions}

The results for the question, How important is the way in which the tickets are available for your favorite team's games? are presented in Table 1.

Table 1. The answers to the question How important is the way in which the tickets are available for your favorite team's games?

\begin{tabular}{|l|l|c|c|c|c|}
\hline \multicolumn{2}{|c|}{} & $\begin{array}{c}\text { Frequ } \\
\text { ency }\end{array}$ & Percent & $\begin{array}{c}\text { Valid } \\
\text { Percent }\end{array}$ & $\begin{array}{c}\text { Cumulative } \\
\text { Percent }\end{array}$ \\
\hline \multirow{4}{*}{ Valid } & Not at all important & 50 & 16.8 & 17.2 & 17.2 \\
\cline { 2 - 6 } & Much less important & 39 & 13.1 & 13.4 & 30.7 \\
\cline { 2 - 6 } & Less important & 88 & 29.5 & 30.3 & 61.0 \\
\cline { 2 - 6 } & Largely important & 90 & 30.2 & 31.0 & 92.1 \\
\cline { 2 - 6 } & Very important & 23 & 7.7 & 7.9 & 100.0 \\
\cline { 2 - 6 } & Total & 290 & 97.3 & 100.0 & \\
\hline \multirow{3}{*}{ Missing } & $\mathbf{9 9 . 0 0}$ & 8 & 2.7 & & \\
\hline Total & & 298 & 100.0 & & \\
\hline
\end{tabular}

As one can see, for 90 spectators, representing $30.2 \%$ of the subjects, said that it is largely important, while 88 spectators said it was less important.

The answers recorded for question 2 are presented in Table 2.

Table 2. The answers to the question How important is for you to get ahead of time the tickets for your favorite team's games?

\begin{tabular}{|l|l|c|c|c|c|}
\hline \multicolumn{2}{|c|}{} & $\begin{array}{c}\text { Freque } \\
\text { ncy }\end{array}$ & Percent & $\begin{array}{c}\text { Valid } \\
\text { Percent }\end{array}$ & $\begin{array}{c}\text { Cumulative } \\
\text { Percent }\end{array}$ \\
\hline Valid & Not at all important & 57 & 19.1 & 19.4 & 19.4 \\
\hline \multirow{7}{*}{} & Much less important & 37 & 12.4 & 12.6 & 32.0 \\
\cline { 2 - 6 } & Less important & 99 & 33.2 & 33.7 & 65.6 \\
\cline { 2 - 6 } & Largely important & 87 & 29.2 & 29.6 & 95.2 \\
\cline { 2 - 6 } & Very important & 14 & 4.7 & 4.8 & 100.0 \\
\cline { 2 - 6 } & Total & 294 & 98.7 & 100.0 & \\
\hline \multirow{3}{*}{ Missing } & $\mathbf{9 9 . 0 0}$ & 4 & 1.3 & & \\
\hline Total & & 298 & 100.0 & & \\
\hline
\end{tabular}

As seen in Table 2, for most spectators this aspect is less important. Percentage-wise, the answers represent $33.2 \%$ of the respondents. For $29.2 \%$, getting tickets ahead of time is largely important.

Table 3 presents the results for the question, How important is for you to come with another person to the game? 
Table 3. The results for the question How important is for you to come with another person to the game?

\begin{tabular}{|l|l|c|c|c|c|}
\hline \multicolumn{2}{|c|}{} & $\begin{array}{c}\text { Freque } \\
\text { ncy }\end{array}$ & Percent & $\begin{array}{c}\text { Valid } \\
\text { Percent }\end{array}$ & $\begin{array}{c}\text { Cumulative } \\
\text { Percent }\end{array}$ \\
\hline Valid & Not at all important & 18 & 6.0 & 6.1 & 6.1 \\
\hline \multirow{5}{*}{} & Much less important & 21 & 7.0 & 7.1 & 13.2 \\
\cline { 2 - 6 } & Less important & 64 & 21.5 & 21.7 & 34.9 \\
\cline { 2 - 6 } & Largely important & 134 & 45.0 & 45.4 & 80.3 \\
\cline { 2 - 6 } & Very important & 58 & 19.5 & 19.7 & 100.0 \\
\cline { 2 - 6 } & Total & 295 & 99.0 & 100.0 & \\
\hline Missing & $\mathbf{9 9 . 0 0}$ & 3 & 1.0 & & \\
\hline Total & & 298 & 100.0 & & \\
\hline
\end{tabular}

To this question, 134 subjects, representing 45\%, answered that it is largely important to come with another person to the game. Only for 18 subjects, this aspect is not at all important.

Table 4 presents the answers to the question How important is your motivation in deciding to go to a game?

Table 4. The answers to the question How important is your motivation in deciding to go to a game?

\begin{tabular}{|l|l|c|c|c|c|}
\hline \multicolumn{2}{|c|}{} & $\begin{array}{c}\text { Freque } \\
\text { ncy }\end{array}$ & Percent & $\begin{array}{c}\text { Valid } \\
\text { Percent }\end{array}$ & $\begin{array}{c}\text { Cumulative } \\
\text { Percent }\end{array}$ \\
\hline \multirow{4}{*}{ Valid } & Not at all important & 9 & 3.0 & 3.0 & 3.0 \\
\cline { 2 - 6 } & Much less important & 15 & 5.0 & 5.1 & 8.1 \\
\cline { 2 - 6 } & Less important & 67 & 22.5 & 22.6 & 30.7 \\
\cline { 2 - 6 } & Largely important & 141 & 47.3 & 47.6 & 78.4 \\
\cline { 2 - 6 } & Very important & 64 & 21.5 & 21.6 & 100.0 \\
\cline { 2 - 6 } & Total & 296 & 99.3 & 100.0 & \\
\hline Missing & $\mathbf{9 9 . 0 0}$ & 2 & .7 & & \\
\hline Total & & 298 & 100.0 & & \\
\hline
\end{tabular}

Table 4 shows that for $47.3 \%$ (141 respondents), the motivation to go to a game is largely important, while for $21.5 \%$ this aspect is very important.

Table 5 presents the answers to the question How important is for you to feel the pleasure/satisfaction of being there during a game? 
Table 5. The answers to the question How important is for you to feel the pleasure/satisfaction of being there during a game?

\begin{tabular}{|l|l|c|c|c|c|}
\hline \multicolumn{2}{|c|}{} & $\begin{array}{c}\text { Freque } \\
\text { ncy }\end{array}$ & Percent & $\begin{array}{c}\text { Valid } \\
\text { Percent }\end{array}$ & $\begin{array}{c}\text { Cumulative } \\
\text { Percent }\end{array}$ \\
\hline \multirow{3}{*}{ Valid } & Not at all important & 3 & 1.0 & 1.0 & 1.0 \\
\cline { 2 - 6 } & Much less important & 18 & 6.0 & 6.1 & 7.1 \\
\cline { 2 - 6 } & Less important & 49 & 16.4 & 16.6 & 23.6 \\
\cline { 2 - 6 } & Largely important & 178 & 59.7 & 60.1 & 83.8 \\
\cline { 2 - 6 } & Very important & 48 & 16.1 & 16.2 & 100.0 \\
\cline { 2 - 6 } & Total & 296 & 99.3 & 100.0 & \\
\hline Missing & $\mathbf{9 9 . 0 0}$ & 2 & .7 & & \\
\hline Total & & 298 & 100.0 & & \\
\hline
\end{tabular}

As seen in Table 5, for 178 subjects, representing 59.7\%, the pleasure of seeing a game in person is largely important. Only for 3 subjects (1\%) this is not at all important.

Table 6 presents the results for the question, How important are for you the aspects that would determine you not to go to a game?

Table 6. The answers to the question How important are for you the aspects that would determine you not to go to a game?

\begin{tabular}{|l|l|c|c|c|c|}
\hline \multicolumn{2}{|c|}{} & $\begin{array}{c}\text { Freque } \\
\text { ncy }\end{array}$ & Percent & $\begin{array}{c}\text { Valid } \\
\text { Percent }\end{array}$ & $\begin{array}{c}\text { Cumulative } \\
\text { Percent }\end{array}$ \\
\hline \multirow{4}{*}{ Valid } & Not at all important & 17 & 5.7 & 5.7 & 5.7 \\
\cline { 2 - 5 } & Much less important & 21 & 7.0 & 7.1 & 12.8 \\
\cline { 2 - 6 } & Less important & 79 & 26.5 & 26.7 & 39.5 \\
\cline { 2 - 6 } & Largely important & 121 & 40.6 & 40.9 & 80.4 \\
\cline { 2 - 6 } & Very important & 58 & 19.5 & 19.6 & 100.0 \\
\cline { 2 - 6 } & Total & 296 & 99.3 & 100.0 & \\
\hline Missing & $\mathbf{9 9 . 0 0}$ & 2 & .7 & & \\
\hline Total & & 298 & 100.0 & & \\
\hline
\end{tabular}

To question 6 , most subjects (121 people) answered that for them, the reasons for not coming to a game should be largely important, while for $19.5 \%$ of the subjects, the reasons should be very important.

\section{Conclusions}

Over the last few years, fans and supporter groups have become one of the most visible aspects of public relations in sports, even though, according to some researchers, this is one of the most underestimated and underused resources. "Considering the importance of the relationship between a team and its fans, it is interesting to note the fact that clubs only rarely manage this relationship in a proactive manner" (Theysohn, Hinz, Nosworthy \& Kirchner, 
2009). The treatment of fans is a key element for the relational approach in sports communication and public relations. Brunning says that the relationships between an organization and its audience should be based on dialog. The results of this study also suggest that the practice of public relations must continue to explore personalization techniques for the organization-public interactions. The relation-building activity is based in too many cases on the idea that one strategy satisfies all needs. "A relational approach based on dialog demands that the organizational actions and communication to be based on relational needs" (Brunning, Dials \& Shirka, 2008).

Sports communication and public relations refer to the fans' feelings and desires in regards to that organization. Considering the results of the research, this author is in complete agreement with Burnton (2009), who wrote that, "It is very important for the game to understand what the spectators want to watch, when they want to watch it and how long they want to watch it for, because we should, at all times, be reacting to the changes in society."

\section{References}

1. BRUNNING, S., D., DIALS, M., SHIRKA, A. (2008). Using Dialog to build organisation-public relationships, engage publics, and positively affect organisational outcomes, Public Relations review (34), p. 29;

2. BURNTON, S. (2009). England's Barmy Army prompts equally barmy reaction, The guardian online;

3. CRONBACH, J. (1977). Educational psychology, San Diego: Harcourt Brace Jocanovic;

4. CUTLIP, S., M., CENTER, A., H., BROOM, G., M. (2006). Effective Public Relations, Upper Saddle River: Prentice Hall;

5. GRUNIG, J., E., HUNT, T. (1984). Managing public relations, Orlando, Florida: Holt, Ricnhart \& Winston;

6. THEYSOHN, S., HINZ, O., NOSWORTHY, S., KIRCHNER, M. (2009). Official supporter clubs: the untapped potential of fan loyalty, International Journal of Sport Marketing and Sponsorship, 10 (4), 303. 


\title{
STUDIU PRIVIND PERCEPTTIA SPECTATORILOR REFERITOARE LA CERINTTELE ŞI NEVOILE ACESTORA ÎN CEEA CE PRIVEŞTE PROMOVAREA EVENIMENTELOR SPORTIVE LA CARE PARTICIPĂ
}

\author{
Ababei Cătălina ${ }^{1}$ \\ 1Universitatea "Vasile Alecsandri" din Bacău, Calea Mărășești 157, 600115, România
}

Cuvinte cheie: competitie, satisfacţie, publicitate.

\section{Rezumat}

Fanii sportului sunt un mecanism foarte important pentru organizatiiile sportive. Aceștia iau rolul de ambasadori ai brandului într-o manieră invidiată de multe organizații orientate spre consum. Iubirea pentru sport arată un grad diferit de loialitate care este greu de reprodus în alte produse de consum. Fanaticii sportului întotdeauna își vor urma echipa favorită, fie că trece prin vremuri bune sau rele. Aceștia își vor susține întotdeauna echipa favorită, pentru că o au în sânge. Ei se asociază cu calitățile echipei favorite. De fapt, întreaga lor identitate este asociată și amestecată cu cea a echipei. Fanii și grupurile de suporteri sunt, așadar, un factor foarte important atunci când vorbim de relații publice și de comunicare în sport. Studiul de faţă încearcă să determine elementele fundamentale pentru ca evenimentele sportive să se bucure de cât mai multi spectatori, care ulterior ar putea deveni adevăraţi suporteri.

\section{Introducere}

Grunig și Hunt (1984) susțin că primul pas într-o strategie de relaţii publice este indentificarea tuturor indivizilor sau grupurilor care au o implicare în interiorul organizației. Acest lucru poate fi reușit prin ,scanarea” mediului folosind sondaje de opinie, studiul mass-mediei, consultarea liderilor politici și liderilor comunității locale, folosind arhive interne și informații de management. Din scanarea mediului are trebui să rezulte o listă de oameni implicați cărora li se pot acorda diferite note, în funcție de gradul de influență pe care aceștia îl au asupra organizației, sau la cât consideră organizația că ar trebui să își modereze impactul față de ei. Resursele ar trebui alocate în conformitate cu această notare, cei primind nota cea mai mare primind cea mai multă atenție. Pe lângă managerierea relației cu factorii implicați, este foarte important ca o organizație să acorde o atenție deosebită publicurilor strategice. Publicurile nu sunt selectate, ci evoluează în funcție de apariția situațiilor. Pe măsură ce aceste publicuri ies în evidență, fiecare va avea un grad diferit de interes în problemă.

Cutlip și colab.(2006) examinează procesul de definire strategică a publicurilor, susținând că ,cheia în definirea publicurilor strategice stă în identificarea felului în care oamenii sunt implicați și afectați de situaţia pentru care programul de intervenție este conceput, care necesită mai mult efort în adunarea informaţiilor decât simpla catalogare a grupurilor de oameni care par să aibă ceva în comun”. Autorii adaugă faptul că este important să înțelegem,,ce 
știu, ce simt și ce fac în relație cu cine și unde sunt" pentru a putea avea obiective utile pentru fiecare public țintă. Acest lucru nu face decât să întărească ideea ui Grunig și Hunt conform căreia este necesară comunicarea bilaterală pentru identificarea publicurilor și punctul lor de vedere asupra problemelor ivite atunci când organizațiile caută să construiască relații solide și durabile cu publicurile cheie. Guvernele, asociațiile, managerii de arene sportive, angajații, sponsorii, reprezentanții media sunt exemple de publicuri implicate.

\section{Material şi metode}

Lucrarea de faţă a avut ca scop identificarea percepţiei publicului sportiv vis a vis de cerinţele şi nevoile acestuia pentru a deveni spectatori fideli ai unui sport sau a evenimentelor sportive în general.

Ipoteza Având în vedere scopul cercetării, am plecat de la următoarea ipoteză de lucru: evidenţierea gradului de importanţă al aspectelor legate de cerințele publicului sportiv ar putea ajuta organizațiile sportive în fidelizarea spectatorilor şi chiar determinarea lor în implicarea activă în activitatea de performanţă.

Obiectivele cercetării: Cercetarea a avut ca obiective principale: stabilirea informaţii pe care am dorit să le aflăm prin intermediul anchetei, intocmirea chestionarului si validarea intrebărilor, stabilirea esantionului supus cercetării si a locului de desfasurare a studiului.

Desfăşurarea cercetării Cercetarea s-a efectuat în luna martie 2016, pe un esantion de 298 de spectatori/suporteri ai competiţiilor de handbal ale clubului Balonmano din Elche, Spania. Cercetarea am realizat-o cu sprijinul direct al antrenorilor clubului mentionat, în paralel cu efectuarea unui stagiu de predare la Universitatea Miguel Hernandez din Elche, Spania. Am ales această disciplină sportivă, deoarece la handbal existau cele mai multe meciuri în acea perioadă, spectatorii putând fi mai uşor de anchetat cu privire la gradul de importanţă al modului in care se realizează comunicarea dintre membrii organizaţiei şi public. Am realizat acestă cercetare la un public din străinătate, urmând ca acelaşi chestionar să fie aplicat şi la spectatorii din România, pentru a vedea asemănările, dar mai ales deosebirile de opinie faţă de aspectele menţionate mai sus.

Metode Principala metoda de cercetare a fost ancheta, iar ca instrument de lucru am utilizat chestionarul sociologic. Acesta afost aplicat direct, înainte de începerea meciurilor. Chestionarul a cuprins un total de 32 de intrebări, vizând:

d) întrebări de identificare;

e) întrebări factuale (prin care aflăm elemente de comportament ale subiecţilor);

f) întrebări de cunoştinţe (prin care incercăm să identificăm cunoştinţele subiecţilor vis a vis de problema supusă atenţiei).

S-a măsurat consistenţa internă prin calcularea coeficientului Cronbach alfa pentru un eşantion format din 298 persoane. Ca urmare a măsurătorilor a rezultat o valoare de 0,713 , cuprins în intervalul de încredere cu limita inferioară 
0,663 şi limita superioară 0,758 , care este o valoare acceptabilă în teoria statistică privitoare la măsurarea consistenţei interne prin intermediul acestui indice. (Cronbach,1977). Prin urmare această valoare indică faptul că tendinţa itemilor este de a măsura aceleaşi variabile.

In lucrarea de faţă am selectat din cele 32 de intrebări, doar şase, acestea vizând gradul de importanţă al unor aspecte care pot deveni factori determinanţi in fidelizarea publicului spectator. Toti participanţii la studiu au fost voluntari. Datele obtinute au fost inregistrate şi prelucrate prin programul SPSS. In studiul de faţă ne vom referi la următorul grup de întrebări din chestionar:

1. Este IMPORTANT MODUL de achiţionare al biletelor/abonamentelor pentru meciurile echipei favorite

Deloc În foarte mică În mică măsură În mare măsură $\quad$ În foarte mare important masură important important important măsură important

\section{Este IMPORTANT sa va achizitionaţi DIN TIMP biletele/abonamentele} pentru meciurile echipei favorite

Deloc I In foarte mică În mică măsură În mare măsură În foarte mare important masură important important important măsură important

3. La meciurile echipei este IMPORTANT să veniţi însoțiţi:

Deloc În foarte mică În mică măsură În mare măsură În foarte mare important masură important important important măsură important

4. Cât de IMPORTANTĂ este MOTIVAŢIA dumneavoastră în hotărârea de a participa la un meci?

Deloc În foarte mică $\quad$ În mică măsură $\quad$ În mare măsură $\quad$ În foarte mare important masură important important important măsură important

5. După un meci de handbal, cât de IMPORTANTĂ este SATISFACTIA/PLACEREA DE A FI PARTICIPAT LA MECI?

Deloc În foarte mică $\quad$ În mică măsură $\quad$ În mare măsură $\quad$ În foarte mare important masură important important important măsură important

6. Cât de IMPORTANTE sunt ASPECTELE care v-ar determina S $\breve{A} N U$ mai veniţi la meci?

$\begin{array}{ccccc}\text { Deloc } & \begin{array}{c}\text { În foarte mică } \\ \text { important }\end{array} & \begin{array}{c}\text { În mică măsură } \\ \text { important }\end{array} & \begin{array}{c}\text { În mare măsură } \\ \text { important }\end{array} & \begin{array}{c}\text { În foarte mare } \\ \text { măsură important }\end{array}\end{array}$ 


\section{Rezultate şi Discuţii}

Prelucrarea răspunsurilor obţinute la intrebarea Este important modul de achiţionare al biletelor/abonamentelor pentru meciurile echipei favorite? Este prezentată în tabelul 1.

Tabel 1. $R$ ăspunsurile obtinute la intrebarea Este important modul de achitionare al biletelor/abonamentelor pentru meciurile echipei favourite?

\begin{tabular}{|l|l|c|c|c|c|}
\hline \multicolumn{2}{|c|}{} & Frequency & Percent & $\begin{array}{c}\text { Valid } \\
\text { Percent }\end{array}$ & $\begin{array}{c}\text { Cumulative } \\
\text { Percent }\end{array}$ \\
\hline Valid & Deloc important & 50 & 16.8 & 17.2 & 17.2 \\
\hline \multirow{7}{*}{} & $\begin{array}{l}\text { În foarte mică } \\
\text { măsură important }\end{array}$ & 39 & 13.1 & 13.4 & 30.7 \\
\cline { 2 - 6 } & $\begin{array}{l}\text { În mică măsură } \\
\text { important }\end{array}$ & 88 & 29.5 & 30.3 & 61.0 \\
\cline { 2 - 6 } & $\begin{array}{l}\text { În mare măsură } \\
\text { important }\end{array}$ & 90 & 30.2 & 31.0 & 92.1 \\
\cline { 2 - 6 } & $\begin{array}{l}\text { În foarte mare } \\
\text { măsură important }\end{array}$ & 23 & 7.7 & 7.9 & 100.0 \\
\cline { 2 - 6 } & Total & 290 & 97.3 & 100.0 & \\
\hline Missing & $\mathbf{9 9 . 0 0}$ & 8 & 2.7 & & \\
\hline Total & & 298 & 100.0 & & \\
\hline
\end{tabular}

După cum se observă, pentru 90 de spectatori, reprezentând 30,2 \% dintre respondeţi, au spus că aspectul este în mare măsură important, în timp ce 88 de spectatori consideră acest lucru în mică măsură important.

Raspunsurile înregistrate la întrebarea 2, sunt prezentate în Tabelul 2.

Tabelul 2. $R$ ăspunsurile obţinute la intrebarea Este important sa va achiziţionaţi din timp biletele/abonamentele pentru meciurile echipei favorite?

\begin{tabular}{|l|l|c|c|c|c|}
\hline \multicolumn{2}{|c|}{} & Frequency & Percent & $\begin{array}{c}\text { Valid } \\
\text { Percent }\end{array}$ & $\begin{array}{c}\text { Cumulative } \\
\text { Percent }\end{array}$ \\
\hline Valid & $\begin{array}{l}\text { Deloc important } \\
\text { în foarte mică } \\
\text { măsură important }\end{array}$ & 57 & 19.1 & 19.4 & 19.4 \\
\cline { 2 - 6 } & $\begin{array}{l}\text { În mică măsură } \\
\text { important }\end{array}$ & 99 & 12.4 & 12.6 & 32.0 \\
\cline { 2 - 6 } & $\begin{array}{l}\text { În mare măsură } \\
\text { important }\end{array}$ & 87 & 29.2 & 29.6 & 95.2 \\
\cline { 2 - 6 } & $\begin{array}{l}\text { În foarte mare } \\
\text { măsură important }\end{array}$ & 14 & 4.7 & 4.8 & 100.0 \\
\cline { 2 - 6 } & Total & 294 & 98.7 & 100.0 & \\
\hline Missing & $\mathbf{9 9 . 0 0}$ & 4 & 1.3 & & \\
\hline Total & & 298 & 100.0 & & \\
\hline
\end{tabular}


Conform tabelului 2, pentru cei multi dintre spectatori aspectul este în mică măsură important. Procentual raspunsurile reprezintă $33,2 \%$ din cei intervievati. Pentru 29,2\% achizitionarea din timp a biletelor este un aspect în mare masură important.

În Tabelul 3 sunt prezentate rezultatele obtinute la întrebarea La meciurile echipei este important să veniţi însoţiţi?

Tabelul 3. Rezultatele privind răspunsurile la intrebarea La meciurile echipei este IMPORTANT să veniţi însoţiţi?

\begin{tabular}{|l|l|c|c|c|c|}
\hline \multicolumn{2}{|c|}{} & Frequency & Percent & $\begin{array}{c}\text { Valid } \\
\text { Percent }\end{array}$ & $\begin{array}{c}\text { Cumulative } \\
\text { Percent }\end{array}$ \\
\hline Valid & Deloc important & 18 & 6.0 & 6.1 & 6.1 \\
\hline \multirow{7}{*}{} & $\begin{array}{l}\text { În foarte mică } \\
\text { măsură important }\end{array}$ & 21 & 7.0 & 7.1 & 13.2 \\
\cline { 2 - 6 } & $\begin{array}{l}\text { În mică măsură } \\
\text { important }\end{array}$ & 64 & 21.5 & 21.7 & 34.9 \\
\cline { 2 - 6 } & $\begin{array}{l}\text { În mare măsură } \\
\text { important }\end{array}$ & 134 & 45.0 & 45.4 & 80.3 \\
\cline { 2 - 6 } & $\begin{array}{l}\text { În foarte mare } \\
\text { măsură important }\end{array}$ & 58 & 19.5 & 19.7 & 100.0 \\
\cline { 2 - 6 } & Total & 295 & 99.0 & 100.0 & \\
\hline Missing & $\mathbf{9 9 . 0 0}$ & 3 & 1.0 & & \\
\hline Total & & 298 & 100.0 & & \\
\hline
\end{tabular}

La această întrebare 134 de intervievati, reprezentand un procent de $45 \%$ au răspuns că este mare măsură important să vină insoţiţi la meciuri. Doar pentru 18 suporteri, aspectul este deloc important.

Tabelul 4. Rezultatele privind răspunsurile la intrebarea Cât de importantă este motivatia dumneavoastră în hotărârea de a participa la un meci?

\begin{tabular}{|l|l|c|c|c|c|}
\hline \multicolumn{2}{|c|}{} & Frequency & Percent & $\begin{array}{c}\text { Valid } \\
\text { Percent }\end{array}$ & $\begin{array}{c}\text { Cumulative } \\
\text { Percent }\end{array}$ \\
\hline Valid & Deloc important & 9 & 3.0 & 3.0 & 3.0 \\
\cline { 2 - 6 } & $\begin{array}{l}\text { În foarte mică } \\
\text { măsură important }\end{array}$ & 15 & 5.0 & 5.1 & 8.1 \\
\cline { 2 - 6 } & $\begin{array}{l}\text { În mică măsură } \\
\text { important }\end{array}$ & 67 & 22.5 & 22.6 & 30.7 \\
\cline { 2 - 6 } & $\begin{array}{l}\text { În mare măsură } \\
\text { important }\end{array}$ & 141 & 47.3 & 47.6 & 78.4 \\
\cline { 2 - 6 } & $\begin{array}{l}\text { În foarte mare } \\
\text { măsură important }\end{array}$ & 64 & 21.5 & 21.6 & 100.0 \\
\cline { 2 - 6 } & Total & 296 & 99.3 & 100.0 & \\
\hline Missing & $\mathbf{9 9 . 0 0}$ & 2 & .7 & & \\
\hline Total & & 298 & 100.0 & & \\
\hline
\end{tabular}


În tabelul 4 sunt prezentate raspunsurile la întrebarea Cât de importantă este motivatia dumneavoastră în hotărârea de a participa la un meci?

În Tabelul 4 se poate observa că pentru un procent de 47,3\% (141 de respondenţi), motivaţia de a participa la meci este în mare măsură importantă, iar pentru 21,5\% aspectul este în foarte mare măsură important.

În Tabelul 5 prezentăm centralizarea răspunsurilor la întrebarea După un meci de handbal, cât de importantă este satisfacţia/placerea de a fi participat la meci?

Tabelul 5. Rezultatele privind răspunsurile la intrebarea După un meci de handbal, cât de importantă este satisfacţia/placerea de a fi participat la meci?

\begin{tabular}{|l|l|c|c|c|c|}
\hline \multicolumn{2}{|c|}{} & Frequency & Percent & $\begin{array}{c}\text { Valid } \\
\text { Percent }\end{array}$ & $\begin{array}{c}\text { Cumulative } \\
\text { Percent }\end{array}$ \\
\hline Valid & Deloc important & 3 & 1.0 & 1.0 & 1.0 \\
\cline { 2 - 6 } & $\begin{array}{l}\text { În foarte mică } \\
\text { măsură important }\end{array}$ & 18 & 6.0 & 6.1 & 7.1 \\
\cline { 2 - 6 } & $\begin{array}{l}\text { În mică măsură } \\
\text { important }\end{array}$ & 49 & 16.4 & 16.6 & 23.6 \\
\cline { 2 - 6 } & $\begin{array}{l}\text { În mare măsură } \\
\text { important }\end{array}$ & 178 & 59.7 & 60.1 & 83.8 \\
\cline { 2 - 6 } & $\begin{array}{l}\text { În foarte mare } \\
\text { măsură important }\end{array}$ & 48 & 16.1 & 16.2 & 100.0 \\
\cline { 2 - 6 } & Total & 296 & 99.3 & 100.0 & \\
\hline Missing & $\mathbf{9 9 . 0 0}$ & 2 & .7 & & \\
\hline Total & & 298 & 100.0 & & \\
\hline
\end{tabular}

Cum se poate vedea în Tabelul 5, pentru 178 de subiecţi, reprezentând un procent de $59,7 \%$, plăcerea de a viziona un meci este in mare măsură importantă. Doar pentru 3 dintre subiecţi (1\%) acest lucru este deloc important.

Tabelul 6. Rezultatele privind răspunsurile la intrebarea Cât de importante sunt aspectele care $v$-ar determina să nu mai veniţi la meci?

\begin{tabular}{|l|l|c|c|c|c|}
\hline \multicolumn{2}{|c|}{} & $\begin{array}{c}\text { Freque } \\
\text { ncy }\end{array}$ & Percent & $\begin{array}{c}\text { Valid } \\
\text { Percent }\end{array}$ & $\begin{array}{c}\text { Cumulative } \\
\text { Percent }\end{array}$ \\
\hline Valid & Deloc important & 17 & 5.7 & 5.7 & 5.7 \\
\cline { 2 - 6 } & $\begin{array}{l}\text { În foarte mică } \\
\text { măsură important }\end{array}$ & 21 & 7.0 & 7.1 & 12.8 \\
\cline { 2 - 6 } & $\begin{array}{l}\text { În mică măsură } \\
\text { important }\end{array}$ & 79 & 26.5 & 26.7 & 39.5 \\
\cline { 2 - 6 } & $\begin{array}{l}\text { În mare măsură } \\
\text { important }\end{array}$ & 121 & 40.6 & 40.9 & 80.4 \\
\cline { 2 - 6 } & $\begin{array}{l}\text { În foarte mare } \\
\text { măsură important }\end{array}$ & 58 & 19.5 & 19.6 & 100.0 \\
\cline { 2 - 6 } & Total & 296 & 99.3 & 100.0 & \\
\hline Missing & $\mathbf{9 9 . 0 0}$ & 2 & .7 & & \\
\hline Total & & 298 & 100.0 & & \\
\hline
\end{tabular}


În Tabelul 6 prezentăm rezultatele privind răspunsurile la intrebarea Cât de importante sunt aspectele care $v$-ar determina să nu mai veniţi la meci?

La întrebarea numărul 6, cei mai mulţi spectatori, respectiv 121 de persoane, au răspuns că pentru ei motivele de a nu veni la meci, ar trebui să fie în mare măsură importante, iar pentru 19,5\% dintre ei, motivele ar trebui sa fie în foarte mare măsură importante.

\section{Concluzii}

În ultimii ani, fanii și grupurile de suporteri au devenit unul din cele mai vizibile aspecte ale relațiilor publice în sport, deși, conform unor cercetători, această resursă este una din cele mai subestimate și mai puțin utilizate. „Având în vedere importanța relaţiei dintre o echipă și suporterii ei este interesant să evidențiem faptul că cluburile nu manageriază această relație într-o manieră proactivă, decât foarte rar” (Theysohn, Hinz, Nosworthy \& Kirchner, 2009).

Tratamentul suporterilor este un element cheie în abordarea relaţională în comunicare și relații publice în sport. Bruning spune că relațiile dintre organizație și publicurile lor ar trebui fondate pe dialog. Aceste rezultate deasemenea sugerează că practica relațiilor publice trebuie să continue să exploreze tehnicile de personalizare a interacțiunilor organizație-public. Activitatea de construire a relațiilor a devenit, în mult prea multe cazuri - o singură strategie satisface toate nevoile. "O abordare relațională bazată pe principii ale dialogului cere ca acțiunile organizaţionale și comunicarea organizațională să fie bazate pe nevoi relaţionale” (Brunning, Dials \& Shirka, 2008). Comunicarea și relațiile publice în sport se referă la sentimentele și dorințele fanilor și grupurilor de suporteri vizavi de organizație.

Avand în vedere rezultatele cercetării suntem pe deplin in accord cu Burnton (2009), care afirma că: „Este foarte important ca jocul să înțeleagă ce vrea spectatorul să vadă, când vrea să vadă, și cât de mult trebuie să dureze, pentru că ar trebui, tot timpul să fim reactivi schimbărilor din societate." 